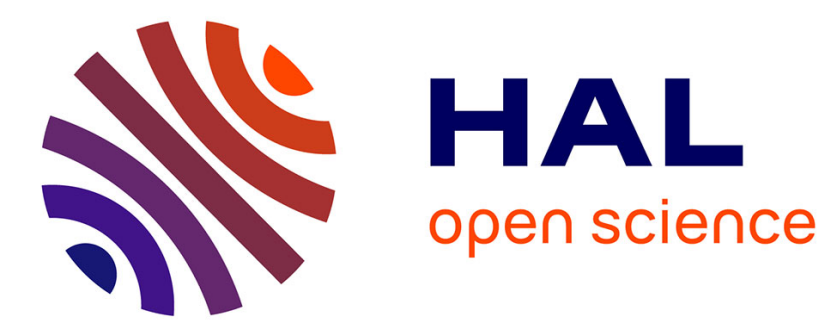

\title{
Efficient Trading Strategies with Transaction Costs
}

Elyès Jouini, Vincent Porte

\section{To cite this version:}

Elyès Jouini, Vincent Porte. Efficient Trading Strategies with Transaction Costs. 2007. halshs00176619

\section{HAL Id: halshs-00176619 \\ https://shs.hal.science/halshs-00176619}

Preprint submitted on 4 Oct 2007

HAL is a multi-disciplinary open access archive for the deposit and dissemination of scientific research documents, whether they are published or not. The documents may come from teaching and research institutions in France or abroad, or from public or private research centers.
L'archive ouverte pluridisciplinaire HAL, est destinée au dépôt et à la diffusion de documents scientifiques de niveau recherche, publiés ou non, émanant des établissements d'enseignement et de recherche français ou étrangers, des laboratoires publics ou privés. 


\title{
Efficient trading strategies with transaction costs
}

\author{
Elyès JOUINI, \\ CEREMADE Université Paris IX-Dauphine* \\ Vincent PORTE, \\ CEREMADE Université Paris IX-Dauphine and \\ G.R.O., Risk Management Group, Crédit Agricole S.A. ${ }^{\dagger}$
}

July 12,2007

\begin{abstract}
In this article, we characterize efficient contingent claims in a context of transaction costs and multidimensional utility functions. The dual formulation of utility maximization helps us outline the key notion of cyclic anticomonotonicity. Moreover, after defining a utility price in this multidimensional setting, we provide a measure of strategies inefficiency and a tool allowing to effectively compute this measure with the help of cyclic anticomonotonicity.
\end{abstract}

Keywords: cyclic anticomonotonicity, utility maximization, transaction costs, utility price.

\section{Introduction}

We consider a general multivariate financial market with transactions costs as in KABANOV ([?]), and we give tools to understand optimal strategies when agents are modelled with preferences following stochastic dominance of order 2. Precisely, an important feature of our analysis is the setting of multidimensional model of the market as well as utility functions. We provide a characterization of efficient contingent claims, i.e. chosen by agents endowed with a multidimensional utility function $U$. We also compute the inefficiency part of a strategy without specifying any utility function.

[] In the literature, these questions were studied in the case of a discrete and complete financial market by Dybvig ([?], and [?]); Jouini and KALlaL

\footnotetext{
*address: Place du Maréchal De Lattre De Tassigny - 75775 Paris Cedex 16 - France; e-mail : jouini@ceremade.dauphine.fr

${ }^{\dagger}$ address: Groupe de Recherche Opérationnelle, Immeuble le Centorial, 18 rue du 4 Septembre - 75002 Paris - France; e-mail : vincent.porte@creditlyonnais.fr ; website : http://gro.creditlyonnais.fr/
} 
([?]) generalizes the results in discrete markets with frictions, and when agents maximize the expected utility of their terminal wealth with respect to a numéraire. These papers show in particular the importance of the notion of anticomonotonicity, translating the intuition that efficient contingent claims are decreasing functions of Arrow-Debreu prices.

Our setting is more general as we consider a continuous financial market, with an infinite probability space, where preferences of agents are represented with the help of a multidimensional utility function, (studied in DeElstra and al. [?]). This multidimensional model of preferences is in accordance with the intuition that not only the liquidation value but also the holdings of the portfolio matters. Moreover, when the preferences of the agent are not only function of the liquidation value of the portfolio, the notion of anticomonotonicity is not relevant anymore. In the main results of this paper, we characterize efficient contingent claims with the notion of cyclic anticomonotonicity, introduced by ROCKAFELLAR ([?]); this is done with the help of the dual formulation of the problem of utility maximization. The paper is organized as follows. Section (1) presents the setting of this paper, and gives the first tools to solve our problem. Section (??) states the principal result of this paper which gives the characterization of strictly efficient contingent claims. We end this paper (section (??)) by the computation of the inefficiency size of a trading strategy.

\section{The financial market}

\subsection{Assets and trading strategies}

Let $T$ be a finite time horizon and $(\Omega,$,$) a probability space endowed$ with a filtration $=\left(F_{t}\right)_{0 \leq t \leq T}$, satisfying the usual conditions. Let $S \triangleq$ $\left(S^{0}, S^{1}, \ldots, S^{d}\right)$ be a continuous semimartingale with strictly positive components; the first component will play the role of numeraire, i.e. is assumed to be constant over time $S^{0}()=$.1 .

In this market, we suppose there exists possibly constant proportional transaction costs. These transaction costs are described with a matrix $\left(\lambda^{i j}\right) \in_{+}^{d+1}$, where ${ }_{+}^{d+1}$ is the set of square matrix with $(\mathrm{d}+1)$ lines with nonnegatives entries. Each coefficient $\lambda^{i j}$ is the proportional cost to transfer value from asset $i$ to asset $j$. Furthermore, this matrix satisfies the following condition:

- $\lambda^{i i}=0$ for all $i \in 0, \ldots, d$

- $\left(1+\lambda^{i j}\right) \leq\left(1+\lambda^{i k}\right)\left(1+\lambda^{k j}\right)$ for all $i, j, k \in 0, \ldots, d$

These conditions translate the economic hypothesis that transaction costs can not be saved by an artificial transit. Following KABANOV([?]), we define the solvency region as the vectors of portfolio holdings such that 
the no bankruptcy condition is satisfied:

$$
K \triangleq\left\{x \in^{d+1} \mid \exists a \in_{+}^{d+1}, x^{i}+\sum_{j=0}^{d}\left(a^{j i}-\left(1+\lambda^{i j}\right) a^{i j}\right) \geq 0 ; i=1, \ldots, d\right\}
$$

This closed convex cone induces a partial ordering on ${ }^{d}$ as:

$$
x_{1} \succeq x_{2} \text { if and only if } x_{1}-x_{2} \in K
$$

We could also introduce the positive polar associated to $K$, defined as

$$
K^{*} \triangleq\left\{y \in^{d+1} \mid\langle x, y\rangle \geq 0, \text { for all } x \in K\right\}
$$

and the partial ordering induced by $K^{*}$ :

$$
y_{1} \succeq_{*} y_{2} \text { if and only if } y_{1}-y_{2} \in K^{*}
$$

A trading strategy on this market is a

tradingstrategyonthismarketisa610-adapted, right-continuous, process

Ltakingvaluesin ${ }_{d+1} . L_{t}^{i j}$ is the cumulative net amount of funds transferred from the asset $i$ to asset $j$ up to the date $t$. Given an initial holdings vector $x \in^{d}$ and a strategy $L$, the portfolio holdings are defined by the dynamics, $610 \mathrm{X}_{t}^{i}=x^{i}+\int_{0}^{t} X_{s}^{i} \frac{d S_{s}^{i}}{S_{s^{-}}^{i}}+\sum_{j=0}^{d}\left(L_{t}^{j i}-\left(1+\lambda^{i j}\right) L_{t}^{i j}\right) 1$ Atradingstrategyissaidadmissibleifitsatisfiest $610 X^{x, L} \succeq 01$ andwedefinethesetof positivecontingentclaimsattainablebyanadmissiblestrategy : $610(x) \triangleq\left\{X \in L^{0}\left(\begin{array}{c}d+1 \\ +\end{array}\right) \mid X=X_{T}^{x, L}\right.$ mbox for an admissible trading strategy $\left.\mathrm{L}\right\} 1 \mathrm{~g}$

values in ${ }_{d+1} . L_{t}^{i j}$ is the cumulative net amount of funds transferred from the asset $i$ to asset $j$ up to the date $t$. Given an initial holdings vector $x \in^{d}$ and a strategy $L$, the portfolio holdings are defined by the dynamics,

$$
X_{t}^{i}=x^{i}+\int_{0}^{t} X_{s}^{i} \frac{d S_{s}^{i}}{S_{s^{-}}^{i}}+\sum_{j=0}^{d}\left(L_{t}^{j i}-\left(1+\lambda^{i j}\right) L_{t}^{i j}\right)
$$

A trading strategy is said admissible if it satisfies the no bankruptcy condition, at each time $t$, i.e.:

$$
X^{x, L} \succeq 0
$$

and we define the set of positive contingent claims attainable by an admissible strategy:

$$
(x) \triangleq\left\{X \in L^{0}\left(\begin{array}{c}
d+1 \\
+
\end{array}\right) \mid X=X_{T}^{x, L} \text { for an admissible trading strategy } \mathrm{L}\right\}
$$




\subsection{Tools of valuation and a Duality result}

\subsubsection{Valuation functions}

In the framework of a market with transaction costs, the valuation of a portfolio with respect to a given asset is not equivalent to the valuation with respect to cash. Thus, different functions of valuation are possible. We could define the liquidation value of a portfolio $x_{0} \in K$ as the maximum cash endowment that we can get from portfolio $x_{0}$ when clearing all the positions in risky assets and paying the transaction costs:

$$
l(x) \triangleq \sup \left\{w \in \mid x \geq w_{1}\right\} .
$$

This definition implies that $l\left(x_{1}\right) \geq l\left(x_{2}\right)$ if and only if $x_{1} \succeq x_{2}$. Moreover, it is possible to reformulate the liquidation function with $K_{0}^{*} \triangleq\left\{y \in K^{*} \mid y^{0}=1\right\}$ :

$$
l(x)=\inf _{y \in K_{0}^{*}} x y
$$

To further comment on this function, we refer to KABAnov( [?]), DeELstRa and al. ([?]) and BOuchard ([?]).

Another function of valuation, which turns out to be very useful in our setting, is the amount of a certain position $x_{0}$ that we can get from the initial holdings vector $x$ :

$$
v_{x_{0}}(x) \triangleq \sup \left\{w \in \mid w x_{0} \preceq x\right\}
$$

In the same way as for the liquidation function, we can give a dual formulation of $v_{x_{0}}($.$) with the set K_{x_{0}}^{*} \triangleq\left\{y \in K^{*} \mid y=\frac{x_{0}}{\left\|x_{0}\right\|^{2}}+y^{\perp}\right\}$. We obtain the following proposition:

Proposition 1.1 Let $x_{0} \in \operatorname{int}(K)$. The set $K_{x_{0}}^{*}$ is compact and $K^{*}$ is the cone generated by $K_{x_{0}}^{*}$. Moreover, the amount $v_{x_{0}}(x)$ of the portfolio $x_{0}$ that can be obtained from the initial holdings vector $x$ is:

$$
v_{x_{0}}(x)=\inf _{y \in K_{x_{0}}^{*}} y x
$$

Proof of the $e$.

t $x_{0} \in \operatorname{int}(K)$; there exists $r_{0}>0$ such that $x_{\lambda}=x_{0} \pm x_{0}^{\perp} \in K$ as soon as $\left|x_{0}^{\perp}\right| \leq r_{0}$. In consequence, if we define $y_{\beta}=x_{0}+\beta x_{0}^{\perp}$, then :

$$
\begin{aligned}
& y_{\beta} x_{\lambda}^{+}={ }^{t}\left(x_{0}\right) x_{0}+\beta^{t}\left(x_{0}^{\perp}\right) x_{0}<0 \text { for } \beta>\beta_{0} \\
& y_{\beta} x_{\lambda}^{-}={ }^{t}\left(x_{0}\right) x_{0}-\beta^{t}\left(x_{0}^{\perp}\right) x_{0}<0 \text { for } \beta<-\beta_{0}
\end{aligned}
$$

We deduce that if $y_{\beta} \in K^{*}$, then $|\beta|<\left|\beta_{0}\right|:$ the set $K_{x_{0}}^{*}$ is compact. The fact that $K^{*}$ is generated by the compact set $K_{x_{0}}^{*}$ is straightforward. Now, for the last item, take $y \in K_{x_{0}}^{*}$ and $w \in$ such that $w x_{0} \preceq x$. We have, by definition of $K^{*}$ :

$$
\langle y, x\rangle-\left\langle y, w x_{0}\right\rangle \geq 0
$$


i.e $\langle y, x\rangle \geq w$ and we deduce that

$$
v_{x_{0}}(x) \leq \inf _{y \in K_{x_{0}}^{*}} y x
$$

To the converse inequality, if $w^{*}>v_{x_{0}}(x)$, we have $w^{*} x_{0} \succ x$. We deduce for $y \in K_{x_{0}}^{*}$ :

$$
\left\langle y, w^{*} x_{0}\right\rangle=w^{*} \geq\langle y, x\rangle
$$

This leads to :

$$
v_{x_{0}}(x) \geq \inf _{y \in K_{x_{0}}^{*}} y x
$$

We introduce also the function, issued from the partial ordering induced by $K^{*}$ :

$$
l^{*}(y) \triangleq \inf _{x \in K,|x|=1} x y
$$

Before ending this paragraph, let us just recall the following properties:

Proposition 1.2 The functions of valuation verify:

- $l^{*}\left(y_{1}\right) \geq 0$ if and only if $y_{1} \succeq 0$.

- $v_{x_{0}}\left(x_{1}\right) \geq 0$ if and only if $x_{1} \succeq 0$.

- $\partial K^{*}=\left\{y \in K^{*} \mid l^{*}(y)=0\right\}$.

- $\partial K=\{x \in K \mid l(x)=0\}$

Proof of the $h$.

e two first items are straightforward. Item (3) and (4) can be found in DeELSTRA and al. ([?]).

\subsubsection{Dual formulation of the super-replication price}

In this paragraph, we give an important result of Kabanov and Last ([?]), allowing us to write the pricing function of contingent claims with a dual formulation.

For some positive contingent claim $C \in L^{0}\left(K,_{T}\right)$, let:

$$
\Gamma(C) \triangleq\left\{x \in^{d+1} \mid X \succeq C \text { for some } X \in(x)\right\}
$$

$\Gamma(C)$ is the set of initial portfolio allowing to construct a strategy which hedges the contingent claim $C$. For a probability

$$
\text { denoting }
$$


()thesetofall-martingales, we introduce the set:

$$
\triangleq\left\{Z \in() \mid \frac{Z_{t}}{S_{t}} \in K^{*}, 0 \leq t \leq T\right\}
$$

With these definitions we can state the following result.

Theorem 1.1 (Kabanov and Last.) Let $S$ be a continuous process in () for some $\sim$. Suppose further that int $\left(K^{*}\right) \neq \emptyset$, Then:

$$
\Gamma(C)=D(C) \triangleq\left\{x \in^{d+1} \mid\left(\hat{Z}_{T} C\right)-\hat{Z}_{0} x \leq 0 \text { for all } Z \in D\right\}
$$

